\title{
3 Research Square

\section{Effect of Nicotiana benthamiana exposed to long- or short-chain perfluoroalkyl substances: Levels, transfer and potential risk analysis}

Huinian Liu

Hunan University

Wenli Hu

Hunan University

Xin Li ( $\square$ hgxlixin@hnu.edu.cn )

Hunan University

Sihui Lu

Hunan University

Fangwen Hu

Hunan University

Yanfen Liu

Hunan University

Tanghuan Xie

Hunan University

Zhuang Zhang

Hunan University

Yanni Xi

Hunan University

Zhu Su

Hunan University

Chang Zhang

Hunan University

\section{Research Article}

Keywords: Emerging Contaminants, PFASs, Health Risk Assessment, Phytotoxicity, Transport, Bioaccumulation

Posted Date: September 29th, 2021

DOI: https://doi.org/10.21203/rs.3.rs-816383/v1 
License: (c) (i) This work is licensed under a Creative Commons Attribution 4.0 International License. Read Full License 


\section{Abstract}

Background: Perfluoroalkyl substances (PFAS) can endanger human health through the food chain. However, the physiological mechanisms of crops exposed to PFAS are still unclear.

Objectives: The physiology, phytotoxicity and accumulation of Solanaceae model crops Nicotiana benthamiana exposed to perfluorooctanoic acid (PFOA), hexafluoropropylene oxide-dimer acid (HFPODA) and their mixed contaminants have been studied.

Results: (i) Biomass, relative electrical conductivity and catalase all decrease; (ii) Chlorophyll, peroxidase, hydrogen peroxide and malondialdehyde all increase; (iii) Superoxide dismutase and soluble sugar both increase and then decrease; $(\mathbb{\nabla})$ The absorption and transport of $\mathrm{K}, \mathrm{Ca}, \mathrm{Mg}$ and $\mathrm{Na}$ are affected, particularly shoots; (V) PFOA has the highest toxicity and bioaccumulation.

Conclusion: PFAS will damages the economic benefits of crops and people's health. So, its production and uses should be curtailed except for essential uses.

Future direction: Substitute substances may be more harmful, so grouping strategies and evaluation framework should be established as soon as possible.

\section{Highlights}

- No competition between PFOA and HFPO-DA, but HFPO-DA is the easiest to transport.

- The toxicity and accumulation of PFASs lead to abnormal plant physiology and affect crop yield.

- Human exposure of PFASs via the food chain of contaminated crops represents a health risk.

- The structural diversity of PFAS poses a challenge to grouping and assessment.

\section{Introduction}

Non-stick cookware was once a miniature of 'better living through chemistry', owing to their excellent surface activity and hydrophobic-oleophobic property given by perfluoroalkyl substances (PFASs).(Gluge et al. 2020; Lindstrom et al. 2011) However, the disadvantages of PFASs were obvious, including persistence,(Cousins et al. 2020b) bioaccumulation(W Zhang et al. 2019) and potential biological toxicity. (Holmquist et al. 2020) Nowadays, PFASs have been detected in the soil in Himalaya Mountains(Wang et al. 2019a) and the Ursus maritimus in polar regions.(Wang et al. 2019b) Researchers gradually realized that these emerging substances were also harmful to human health(Cardenas et al. 2017; Liu et al. 2021) and the ecological environment.(H Chen et al. 2020) Perfluorooctanoic acid (PFOA) was the most widely used and researched PFASs. It was estimated that PFOA had a half-life of 3.8 years in the human body(Olsen et al. 2007) and was listed as a new persistent organic pollutants (POPs) in 2019 ("Stockholm Convention").(Hogue 2019) Furthermore, PFOA had been phased out in European Union, 
North America, China and other regions or countries. The main elimination policy at this stage was to completely replaced long-chain PFASs (number of carbon atoms $\geq 7$ ) with short-chain PFASs $(C<7)$. For instance, a quintessential case of PFOA $(C=8)$ substitute substance was hexafluoropropylene oxidedimer acid [HFPO-DA ( $C=6)$, also known as GenX]. Both PFOA and HFPO-DA had low volatility and high solubility, and could be retained in various media for a long time once entering into environment.(Tian et al. 2018; Xiao 2017) Due to the long-term retention of PFOA and HFPO-DA in the environment, this might increase their accumulation and transfer from the medium to the organism.(Houtz et al. 2013)

To our knowledge, a multitude of studies had focused on the accumulation and toxicity of PFOA and HFPO-DA in persons(Gebbink and Van Leeuwen 2020; Wen et al. 2020) and animals.(Blake et al. 2020; Coperchini et al. 2020; Gaballah et al. 2020; Hassell et al. 2020) Some investigations had also been conducted that other PFASs could be easily absorbed by crops.(Gredelj et al. 2020b; Liu et al. 2019; W Wang et al. 2020; Xiang et al. 2018) Crops belong to the starting point of the food chain and constitute the first trophic level. According to the principle of food webs and energy flow, once PFOA and HFPO-DA were absorbed by crops, they could enter into various nutrition levels through bioaccumulation and biomagnification, especially for humans. However, the precise environmental health risks and economic losses caused by PFOA and HFPO-DA in crops production were still unknown. The occurrence of these hazards was closely related to the physiological responses of crops. In order to solved this knowledge gap, this experiment mainly designed the model plant Nicotiana benthamiana. Many pioneering researches had used it as standard materials (e.g., photoperiod, nutrient absorption and genetic modification, etc.).(Goodin et al. 2008; J Li et al. 2019; Shan et al. 2013) N. benthamiana was also closely associated with the research of important agronomic crops, such as Capsicum annuum L., Solanum lycopersicum, Solanum melongena L. and Solanum tuberosum. This significant helped us to use these characteristics to explored the physiological and biochemical regulations of how crops tolerated, accumulated and responded under PFASs stress.

This study proposes to deeply understand the influence and damage mechanism of PFOA, HFPO-DA and their mixture pollutants on $N$. benthamiana; Predict the effects and harm of PFASs in crops production. And conducted the following work: (i) Investigating different concentrations stress of PFOA, HFPO-DA and their mixed contaminants ( $v / v, 1: 1)$ on the germination. (ii) Finding morphological effects, phytotoxicity, uptake rate and translocation efficiency of each group in seedlings. (iii) Revealing physiological and biochemical regulations of seedlings under stress. Including biomass; Relative electrical conductivity; Chlorophyll content; Catalase (CAT), Superoxide dismutase (SOD) and Peroxidase (POD) activity; Hydrogen peroxide $\left(\mathrm{H}_{2} \mathrm{O}_{2}\right)$, Malondialdehyde (MDA) and Soluble sugar content; And potassium $(\mathrm{K})$, calcium $(\mathrm{Ca})$, magnesium $(\mathrm{Mg})$ and sodium $(\mathrm{Na})$ translocation were also measured.

\section{Materials And Methods}

\subsection{Main chemicals}


PFOA (96\% pure, CAS no. 335-67-1) and HFPO-DA (97\% pure, CAS no. 13252-13-6) were purchased from official website of MACKLIN reagent, Shanghai, China (http://www.macklin.cn/).

\subsection{Growth conditions}

Placed the vernalized seeds in a petri dish containing half-strength Murashige and Skoog (1/2 MS) agar medium, (CH Chen et al. 2020) $\mathrm{pH}=5.8$ and different concentrations of PFOA, HFPO-DA or (PFOA + HFPODA) $(0,5,15,50,150$ and $350 \mathrm{mg} / \mathrm{L})$. Finally, placed vertically on racks and incubated with a 16/8 hours light/dark period with a light intensity of $120 \mu \mathrm{mol} /\left(\mathrm{m}^{2} \cdot \mathrm{s}\right)$ at $22 \pm 2{ }^{\circ} \mathrm{C}$ for one, two and three weeks.

\subsection{Calculation of seed germination index}

Did three parallel experiments, and each group would germinate 100 seeds. Daily germination: count the number of germinated seeds in the three groups of experiments every day until no seeds germinated.

\Germinating percentage (GP):

$\mathrm{GP}=\frac{\text { Numberofgerminatedseeds }}{\text { Totalnumberofseeds }} * 100 \%$

$\triangle$ Relative Germinating percentage (RGP):

$\mathrm{RGP}=\frac{\text { StressedGP }}{\text { NostressedGP }} * 100 \%$

ه Germinating energy (GE):

$\mathrm{GE}=\frac{\sum(\text { Gtmax })}{\text { Totalnumberofseeds }} * 100 \%$ (Gt is the number of germinating seeds per day.)

\ Relative Germinating energy (RGE):

$\mathrm{RGE}=\frac{\text { StressedGE }}{\text { NostressedGE }} * 100 \%$

$\otimes$ Germinative index (GI):

$\mathrm{GI}=\sum \frac{\mathrm{Gt}}{\mathrm{Dt}} * 100 \%$ (Dt is the number of days of seeds.)

$\nabla$ Relative Germinative index (RGI):

$\mathrm{RGI}=\frac{\text { StressedGI }}{\text { NostressedGI }} * 100 \%$

Q Vitality index (VI):

$\mathrm{VI}=\mathrm{GI} * \mathrm{~S} * 100 \%$ (S is the average length grown to the 7 th day.) 
\Relative Vitality index (RVI):

$\mathrm{RVI}=\frac{\text { StressedVI }}{\text { NostressedVI }} * 100 \%$

$\nabla$ Inhibition rate (plants length)

Inhibitionrate $=\frac{\text { Nostressed }- \text { Stressed }}{\text { Nostressed }} * 100 \%$

\subsection{Extraction and analysis of target pollutants}

A method for the determination of PFOA, HFPO-DA and (PFOA + HFPO-DA) in shoot and root samples was developed.(CH Chen et al. 2020; Fan et al. 2020) Additional details was given in the Supplementary Information (S1).

Since the $N$. benthamiana had visible roots and shoots, the translocation factors (TFs) for PFOA, HFPODA and (PFOA + HFPO-DA) were designed by using the following formula:(Zhou et al. 2017)

पTFs $=\frac{\text { Concentraioninshoots }(\mathrm{mg} / \mathrm{kg})}{\text { Concentraioninroots }(\mathrm{mg} / \mathrm{kg})}$

Bioconcentration factors (BCFs). BCFs had been calculated to characterize plant uptake and translocation efficiency of PFASs.

$\square \mathrm{BCFs}=\frac{\text { Concentraioninrootsorshoots }(\mathrm{mg} / \mathrm{kg})}{\text { Concentraionin } \square \text { MSmedium }(\mathrm{mg} / \mathrm{L})}$

\subsection{Agronomic traits in seedling stage}

The experiment was also repeated three times.

a. Counted the root and shoot lengths of 10 plants and took the average.

b. Number of lateral roots was the sum of 10 plants.

c. After 3 weeks of growth of the $N$. benthamiana, samples were collected. Freeze and vacuum dry at $-30^{\circ} \mathrm{C}$.

\subsection{Determination of physiological indicators}

$\nabla$ Watercontent $=\frac{(\mathrm{FW}-\mathrm{DW})}{\mathrm{FW}} * 100 \%$

$\nabla$ Relativeelectricalconductivity $=\frac{\mathrm{R} 1}{\mathrm{R} 2} * 100 \%$ (Additional details was gave in the $\mathbf{S} 1$ )

Chlorophyll content: determined with chlorophyll meter (SPAD-502Plus, Konica Minolta, Japan).

CAT, SOD and POD activity; $\mathrm{H}_{2} \mathrm{O}_{2}, \mathrm{MDA}$ and soluble sugar content: the above indicators were determined using the kit (Table 1). 
$\mathrm{K}, \mathrm{Ca}, \mathbf{M g}$ and Na were measured, additional details were giving in the $\mathbf{S} \mathbf{1}$.

\subsection{Statistical analysis}

SPSS 17.0 software was used to perform analysis of variance (One-way ANOVA) on the measured data. The least significant difference method (LSD method) was used to make multiple comparisons of the significance of the difference between different treatments for each indicator. The mapping analysis software was Origin Pro 2020b.

\section{Result And Discussion}

\subsection{Effects of PFASs on germination}

Under the stress of PFASs, the germination time of a part of seeds was prolonged, and some seeds could not germinate. Although the seeds in different concentrations $(0,5,15,50,150$ and $350 \mathrm{mg} / \mathrm{L})$ of PFOA, HFPO-DA and (PFOA + HFPO-DA) stress were reached the peak of germination on the 3rd day, (85.0, 83.0, $81.7,74.3,74.3,0 \%),(85.0,84.0,82.0,82.0,73.7,59.0 \%)$ and $(85.0,80.0,83.7,71.7,70.0,16.7 \%)$, respectively (Fig. 1, a to $\mathrm{c}$ ), the germination time of them differed greatly. For example, when the concentrations of PFOA and (PFOA + HFPO-DA) overtopped $50 \mathrm{mg} / \mathrm{L}$, the germination of seeds was hindered, and the germination time might be extended by up to 5 days (Fig. 1, a/c). Then, the results were indicative of low concentrations of PFASs $(5,15 \mathrm{mg} / \mathrm{L})$ did not affect the GP and GE, but the germination would be significantly inhibited when the concentration of PFASs increased, GP: (PFOA: 98.3, 98.0, 97.7, 95.3, 91.3, 28.7\%), (HFPO-DA: 98.3, 98.0, 97.3, 97.3, 95.3, 92.3\%) and [(PFOA + HFPO-DA): 98.3, 96.0, 96.7, 95.0, 95.7, 75.3\%], respectively (Fig. 1, d); GE: (PFOA: 85.0, 83.0, 81.7, 74.3, 74.3, 14.0\%), (HFPO-DA: 85.0, 84.0, 82.0, 82.0, 73.7, 59.0\%) and [(PFOA + HFPO-DA): 85.0, 80.0, 83.7, 71.7, 70.0, 37.0\%], respectively

(Fig. 1, e). And the effect of PFASs on the GI and VI were proportional to the concentration, GI: (PFOA: 31.7, 31.4, 31.2, 30.0, 28.6, 5.1\%), (HFPO-DA: 31.7, 31.5, 31.2, 31.2, 30.0, 27.5\%) and [(PFOA + HFPO-DA): 31.7, 30.7, 31.1, 29.4, 28.8, 17.0\%], respectively (Fig. 1, f); Vl: (PFOA: 64.3, 57.4, 55.0, 35.7, 15.5, 0\%), (HFPO-DA: 64.3, 60.1, 59.4, 53.0, 36.2, 5.1\%) and [(PFOA + HFPO-DA): 64.3, 56.6, 48.5, 39.2, 30.2, 2.0\%)], respectively (Fig. 1, g). Finally, the low concentrations of PFASs $(5,15 \mathrm{mg} / \mathrm{L})$ had no effect on the RGP, RGE and RGI (S-Fig. 1, a to c), but had a significant effect on RVI (S-Fig. 1, d). And the high concentrations of PFASs ( $\geq 50 \mathrm{mg} / \mathrm{L}$ ) had a significant impact on the RGP, RGE, RGI and RVI (S-Fig. 1).

The results suggested that the toxic effects of three PFASs on germination were PFOA $>$ (PFOA + HFPODA) > HFPO-DA. Low concentrations of the PFASs $(5,15 \mathrm{mg} / \mathrm{L}$ ) have weaker toxicity to seeds. (Zhang et al. 2020) The feasible reason was that the effect of inhibiting the production of reactive oxygen species (ROS) and reactive nitrogen species (such as NO and others) in the seeds was not obvious.(Xie et al. 2020) This leads to a slight decrease in the level of oxidative stress, which slows down the rate of nutrient decomposition, thereby reducing nutrient supply and slowing down the breathing rate.(Liu et al. 2020) High concentrations of PFASs (>50 mg/L) have strong inhibitory effects on germination.(Gredelj et al. 2020a) It might be that the stress had a greater impact on cell osmotic regulation, the composition of membrane lipids and fatty acids, and the activities of physiological metabolic enzymes.(P Li et al. 2019) 


\subsection{Effects of PFASs on the seeding growth}

Researched on seeding found that the concentration increased, the growth rate of shoots (Final inhibition rate: 18.2, 25.6, 61.8, 91.5\%, D, respectively) and roots (Final inhibition rate: 7.7, 17.0, 57.8, 84.9\%, D, respectively) were decreased under the PFOA stress (Fig. 2, a). If the HFPO-DA exposure levels were the same or greater than $15 \mathrm{mg} / \mathrm{L}$, it would significantly inhibit the shoots (Final inhibition rate: 18.4, 21.0, $32.4,62.0,88.1 \%$, respectively) and roots (Final inhibition rate: 1.4, 0.3, 32.6, 58.0, 95.2\%, respectively) growth (Fig. 2, b). Under the stress of (PFOA + HFPO-DA), the shoots (Final inhibition rate: 13.3, 20.4, 50.3, 72.7, $99.0 \%$, respectively) and roots (Final inhibition rate: $5.7,12.3,45.6,79.9,98.2 \%$, respectively) growth were all inhibited (Fig. 2, c).

Next, the work indicated that with the increase of PFOA concentration, the germination time of lateral roots was prolonged and the number of lateral roots was decreased (Average total number: 38, 27, 19, 11, $\mathrm{N}$, D, respectively), the result showed significant differences (Fig. 2, d). Under the HFPO-DA stress, low concentration $(5 \mathrm{mg} / \mathrm{L})$ had little effect on the germination and growth of lateral roots. When the concentration increased, the germination and growth of lateral roots (Average total number: $38,36,29,15$, 10, 5, respectively) were both inhibited (Fig. 2, e). Under the stress of (PFOA + HFPO-DA), the growth of lateral roots (Average total number: $38,34,25,13,8, \mathrm{~N}$, respectively) were inhibited obviously, too. When the concentration was equal or greater than $15 \mathrm{mg} / \mathrm{L}$, there was a quite difference. Once the concentration was equal or more than $350 \mathrm{mg} / \mathrm{L}$, the lateral roots could not germinate (Fig. 2, f). Besides, the growth morphology of $N$. benthamiana after exposed 7 days, 14 days and 21 days shown in S-Fig. 2 .

Above results illustrated that the toxicity of PFASs to seedlings was: PFOA $>($ PFOA + HFPO-DA $)>$ HFPODA. Tolerance had been widely used to evaluated the ability of crops under biological and abiotic stress. (CH Chen et al. 2020; Li et al. 2020) The difference between stress group and control group was more significant, which was manifested as weaker tolerance and greater damage to crops. In general, PFASs exposure levels were equal or greater than $15 \mathrm{mg} / \mathrm{L}$, the tolerance of $N$. benthamiana decreased rapidly. It was well known that the growth and antioxidant defense responses of different species might be different. Differences in defense capabilities might result in different tolerance and phytotoxicity. However, the $N$. benthamiana used in this experiment and $C$. annuum L., S. lycopersicum, S. melongena L., S. tuberosum and other crops were belonging to the Solanaceae family, and their morphology, life form, reproduction mode, internal structure and genes were the same or similar. Therefore, above results have a high reference value.

\subsection{Bioaccumulation and translocation of PFASs}

It was found that the accumulation of PFOA, HFPO-DA and (PFOA + HFPO-DA) was directly proportional to the stress concentration (Shoots: 0, 41.3, 155.7, 457.3, N, D mg/kg; Roots: 0, 164.7, 465.7, 1324.0, N, D mg/kg) (Fig. 3, a), (Shoots: 0, 37.0, 97.0, 318.1, 1022.7, N mg/kg; Roots: 0, 47.7, 140.3, 418.0, 1182.7, N mg/kg) (Fig. 3, b) and [Shoots: PFOA (0, 22.3, 73.0, 231.0, 716.7, N mg/kg); HFPO-DA (0, 18.3, 50.3, 168.0, 522.7, N mg/kg)]; [Roots: PFOA (0, 72.3, 247.3, 654.3, 1316.7, N mg/kg); HFPO-DA (0, 24.3, 70.3, 218.0, 604.7, $\mathrm{N} \mathrm{mg/kg)]} \mathrm{(Fig.} \mathrm{3,} \mathrm{C),} \mathrm{respectively.} \mathrm{Under} \mathrm{the} \mathrm{same} \mathrm{concentration,} \mathrm{the} \mathrm{HFPO-DA} \mathrm{had} \mathrm{the} \mathrm{lowest}$ 
accumulation and the PFOA had the highest accumulation. Meanwhile, the PFASs were more likely accumulated in roots.

And TFs was an overall upward trend (PFOA: 0.25, 0.33, 0.35, N, D) (Fig. 3, d), (HFPO-DA: 0.78, 0.69, 0.76, 0.86, N) (Fig. 3, e) and [(PFOA + HFPO-DA): PFOA $(0.31,0.30,0.35,0.54, \mathrm{~N})$; HFPO-DA $(0.75,0.71,0.77$, $0.86, \mathrm{~N})$ ] (Fig. $3, \mathrm{f})$, respectively, but the transport ability was weak (TFs $<1)$. At the same concentration, the TFs of the HFPO-DA exposed could be higher than those of the PFOA-stressed. Besides, BCFs of PFOA, HFPO-DA and (PFOA + HFPO-DA) was comparable (Shoots: 32.9, 31.0, 26.5, N, D; Roots: 8.3, 10.4, 9.1, N, D), (Shoots: 9.5, 9.4, 8.4, 7.9, N; Roots: 7.4, 6.5, 6.4, 6.8, N) and (Shoots: 19.3, 21.2, 17.4, 12.8, N; Roots: 8.1, 8.2, 8.0, 8.3, N) (S-Table 2), respectively, with the highest BCFs under PFOA exposure group.

The bioaccumulation characteristics of PFASs in N. benthamiana and organs demonstrated that there were three main parts related to root absorption: apoplasts (space outside the cell membrane), symplasts (space inside the cell membrane) and plant vacuoles (storage organelles). In order to be transported through the xylem sap to the upper part of the crop, PFASs must passed through the cell membrane into the symplast, and entered the xylem through the casparian zone.(Muller et al. 2016) The paper also showed that PFASs were more easily enriched in roots.(TT Wang et al. 2020b; W Zhang et al. 2019) With high bioaccumulation of the PFOA might be interpreted by their better hydrophobicity and stays in the crops body longer.(Zhu and Kannan 2019) In addition, the observed root concentrations for PFOA and HFPO-DA was consequently mainly flow from adsorption, but the effective sucked in the roots was a portion of the observed.

Due to the biological amplification effect of PFASs in the food chain,(Sznajder-Katarzynska et al. 2018) the higher the nutrient level is, the higher the PFASs content should be, in especial in mammals. And the effect of bioaccumulation, the human beings were exposed to higher concentration of food chain and accumulated for a long time.(Semerad et al. 2020; TT Wang et al. 2020a) Now, there a multitude of investigations on high-trophic species, and few studies on low-trophic species.(Wen et al. 2013) This research completes the gap in the field of the first trophic level research. However, the strength of the interaction between single and compound PFASs stresses was not concluded. The different chain lengths of PFASs, both the molecular size and polarity of the molecules vary. PFOA was increasingly lipophilic and might be adsorbed onto crop roots surface quickly and strongly, while HFPO-DA might diffused through the plasma membranes of roots cell at higher concentration as a result of their smaller molecular size.(Pi et al. 2017) Moreover, crops might be under PFOA stress with higher BCFs, but under HFPO-DA stress the transport capacity was higher, this mean that the potential harm of HFPO-DA would be greater. (Gomis et al. 2018) In general, PFOA and HFPO-DA manifested a preference for bioaccumulation in different tissues, which should be further demonstrated.

\subsection{Physiological response to PFASs stress}

\subsubsection{Regulations of the biomass}

The biomass and water content decreased. PFOA, HFPO-DA and (PFOA + HFPO-DA) still significantly impacted the weights, especially PFOA (Fig. 4, a). As the exposure levels increased, the water content 
decreased, (PFOA: 95.4, 95.3, 94.5, 93.8, 89.6\%, D), (HFPO-DA: 95.4, 95.4, 95.5, 95.0, 94.4, 90.8\%) and [(PFOA + HFPO-DA): 95.4, 95.5, 95.0, 94.0, 92.0, 90.3\%], respectively (Fig. 4, b).

In the above study, low concentration ( 5 or $15 \mathrm{mg} / \mathrm{L}$ ) HFPO-DA group stress could promote the growth of seedlings.(Gredelj et al. 2020a) The biomass and water content under different levels and each group types of PFASs also demonstrated differences. This was probably because PFASs could destroyed respiration and photosynthesis, affected nutrient and water uptake and transport, disrupted gene and protein expression, and enhanced ROS accumulation and lipid peroxidation. These would leaded to physiological metabolism disorder, affected the growth and development of crops.

\subsubsection{Regulations of conductivity and chlorophyll in leaves}

The relative electrical conductivity of leaves increased significantly. The PFOA, HFPO-DA and (PFOA + HFPO-DA) exposure levels increased (30.1, 37.7, 39.0, 44.2, 48.8\%, D), (30.1, 36.8, 37.1, 43.1, 47.3, 59.0\%) and $(30.1,37.6,38.6,42.7,49.0 \%, \mathrm{~N})$, respectively (Fig. 5, a). When the stress time prolonged, the relative conductivity of leaves also increased (PFOA: 28.4, 39.7, 57.6, 59.9\%, N, D), (HFPO-DA: 28.4, 36.4, 49.6, 54.0, 59.7\%, N) and [(PFOA + HFPO-DA): 28.4, 37.6, 51.8, 53.7, 60.4\%, N], respectively (Fig. 5, b). And the chlorophyll content illustrated a total downward trend. 14 days after exposure: (PFOA: 17.5, 14.2, 13.1, 13.0, 2.6, D SPAD), (HFPO-DA: 17.5, 13.1, 16.8, 19.1, 12.3, 7.6 SPAD) and [(PFOA + HFPO-DA): 17.5, 12.9, 13.9, 12.9, 5.5, N SPAD], respectively (Fig. 5, C). 21 days after exposure: (PFOA: 16.0, 15.0, 15.4, 10.8, 0.7, D SPAD), (HFPO-DA: 16.0, 15.1, 15.5, 13.6, 11.9, 1.4 SPAD) and [(PFOA + HFPO-DA): 16.0, 14.7, 14.4, 13.0, 10.3, N SPAD], respectively (Fig. 5, d). Compared with each group, the chlorophyll content demonstrated a trend of first increased and then decreased in a short time under the HFPO-DA stress (Fig. 5, c). At last, while on the same concentration ( $\geq 15 \mathrm{mg} / \mathrm{L}$ ), the chlorophyll content of leaves was the highest under the HFPO-DA stress.

The relative conductivity of normal leaves was significantly different from the stressed. The results showed that when crops tissue was injured by stress, the cell membrane was damaged by mechanical damage and membrane lipid peroxidation, resulting in the destruction of membrane structure, the increase of membrane permeability and the exosmosis of intracellular substances (especially electrolytes), resulting in the increased of relative conductivity of tissue soaking solution.(Chow et al. 2018) Beside chlorophyll content decreased with PFASs increased, might signify PFASs involvement (phytotoxic) in modulating about physiological responses.(Moulick et al. 2017) This was because the increased of chlorophyll degradation (etiolation) or the inhibition of chlorophyll synthesis.

\subsubsection{Regulations of CAT, SOD, POD, $\mathrm{H}_{2} \mathrm{O}_{2}$, MDA and soluble sugar}

The CAT showed an overall downward trended under the stress of PFOA, HFPO-DA and (PFOA + HFPODA) $(31.3,27.4,24.8,23.7, \mathrm{~N}, \mathrm{D} \mathrm{U} / \mathrm{g} \cdot \mathrm{min}),(31.3,30.0,28.7,26.7,15.7, \mathrm{~N} \mathrm{U} / \mathrm{g} \cdot \mathrm{min})$ and $(31.3,28.9,27.1$, 25.6, 12.7, N U/g.min), respectively (Fig. 6, a). The SOD and soluble sugar illustrated a trend of first increased and then decreased (PFOA: 64.0, 82.5, 88.7, 88.6, N, D U/g.min; 7.2, 7.8, 9.2, 9.7, N, D mg/g), (HFPO-DA: 64.0, 67.2, 78.0, 81.1, 70.6, N U/g.min; 7.2, 7.4, 8.0, 8.9, 8.1, $\mathrm{N} \mathrm{mg/g}$ ) and [(PFOA+ HFPO-DA): 
64.0, 68.6, 80.0, 83.1, 75.2, N U/g.min; 7.2, 7.7, 8.6, 9.5, 9.1, N mg/g], respectively (Fig. 6, b/f). The POD, $\mathrm{H}_{2} \mathrm{O}_{2}$ and MDA demonstrated an overall upward trend (PFOA: 51.1, 63.8, 79.9, 107.7, N, D U/g.min; 1.6, 2.2, 3.1, 4.4, N, D umol/g; 8.1, 9.9, 10.8, 12.5, N, D umol/g), (HFPO-DA: 51.1, 57.4, 73.3, 95.3, 142.9, N $\mathrm{U} / \mathrm{g} \cdot \mathrm{min} ; 1.6,1.8,2.6,3.2,4.4, \mathrm{~N} \mathrm{umol} / \mathrm{g} ; 8.1,8.5,9.7,11.1,13.2, \mathrm{~N} \mathrm{umol} / \mathrm{g})$ and [(PFOA + HFPO-DA): 51.1, 61.2, 75.6, 97.8, 150.1, N U/g.min; 1.6, 2.0, 2.8, 3.5, 4.8, N umol/g; 8.1, 9.4, 10.2, 11.4, 13.5, N umol/g], respectively (Fig. 6, c/d/e). All results indicated that the physiological indexes under the HFPO-DA stress were the lowest, then under the PFOA stress were the highest.

\section{CAT manifested a downward trend, SOD increased first and then decreased, POD illustrated an upward}

trend. CAT, SOD and POD enzymes form an antioxidant system during the crops metabolism, and the three enzymes can effectively remove active oxygen free radicals.(Zhao et al. 2017) The increase and decrease of antioxidant enzyme activity were related to the resistance of crops. With stronger resistance could maintain the enzyme activity at a higher level under favorable conditions for themselves.(W Zhang et al. 2019) The CAT enzyme activity declines faster under high concentration (> $50 \mathrm{mg} / \mathrm{L}) \mathrm{stress}$. It showed that as the stress concentration increases, the harmful free radicals produced exceed the normal disproportionation ability, the antioxidant enzyme system was destroyed, and the enzyme activity decreases. SOD enzyme activity gradually increased under low concentration (<50 mg/L) stress, and rapidly decreased under high concentration (>50 mg/L) stress.(Moradi et al. 2019) It showed that under the treatment of low concentration of the PFASs, the defense function in the plant was stimulated, and the enzyme activity rises rapidly to deal with the harm caused by the increase of active oxygen triggered by PFASs. However, as the stress concentration increases, PFASs accumulate in the plant, causing the crop's physiological metabolism to be disordered, and the enzyme activity was inhibited and begins to decline. POD enzyme activity has been increasing, indicating that under the current concentration of the PFASs treatment, the increase in enzyme activity catalyzes the oxidation of phenols and amines by $\mathrm{H}_{2} \mathrm{O}_{2}$ eliminating the toxic effects of $\mathrm{H}_{2} \mathrm{O}_{2}$, phenols and amines. So, SOD and POD enzymes play an active role in this process.

$\mathrm{H}_{2} \mathrm{O}_{2}$ demonstrated an overall upward trend. The increased of $\mathrm{H}_{2} \mathrm{O}_{2}$ oxidizes biological macromolecules, such as nucleic acid and protein in the cell, and damages the cell membrane, thereby accelerating the aging and disintegration of cells. It illustrated that as the concentration increases, the toxic effect of PFASs on crops was stronger.(CH Chen et al. 2020)

The MDA illustrated an overall upward trend. While the crops was stressed by PFASs, with the increase of the concentration, the higher the degree of peroxidation of cell membrane plasm, the greater the degree of cell membrane damage.(Zhang and Kirkham 1993)

Soluble sugar manifested a trend of first increased and then decreased. When the crops were stressed by low concentrations of the PFASs, they could promote the synthesis of soluble sugars in seedlings by adjusting the balance of carbon and nitrogen metabolites, which enhances resistance.(Gill et al. 2003) As the concentration increases, the cell structure of crops would be destroyed, which leads to the imbalance of osmotic regulation and hinders the synthesis of soluble sugar. 


\subsubsection{Regulations of mineral elements absorption and transport}

$\mathrm{K}, \mathrm{Ca}$ and $\mathrm{Mg}$ content generally illustrated a trend of first increased and then decreased. The $\mathrm{Na}$ content had a rose trend in the shoots, but did not change much in the roots. To sum it up, the stress of PFOA, HFPO-DA and (PFOA + HFPO-DA) significantly effects on shoots. For K: $(25.5,28.5,21.9,16.7, \mathrm{~N}, \mathrm{D} \mathrm{mg} / \mathrm{g})$, $(25.5,29.4,24.0,19.2,10.8, \mathrm{~N} \mathrm{mg} / \mathrm{g})$ and $(25.5,27.7,22.6,17.5,9.1, \mathrm{~N} \mathrm{mg} / \mathrm{g})$, respectively (Fig. 7, a); For Ca: $(8.1,9.6,8.1,6.1, \mathrm{~N}, \mathrm{D} \mathrm{mg} / \mathrm{g}),(8.1,9.8,9.0,7.4,5.3, \mathrm{~N} \mathrm{mg} / \mathrm{g})$ and $(8.1,9.4,8.5,6.7,4.9, \mathrm{~N} \mathrm{mg} / \mathrm{g})$, respectively (Fig. 7, b); For Mg: (2.6, 2.5, 2.1, 1.4, N, D mg/g), (2.6, 2.8, 2.3, 1.9, 1.3, N mg/g) and (2.6, 2.6, 2.3, 1.5, 1.3, N mg/g), respectively (Fig. 7, c); For Na: $(0.2,0.2,0.4,0.5, \mathrm{~N}, \mathrm{D} \mathrm{mg} / \mathrm{g}),(0.2,0.2,0.3,0.4,0.6, \mathrm{~N}$ $\mathrm{mg} / \mathrm{g})$ and $(0.2,0.2,0.4,0.5,0.8, \mathrm{~N} \mathrm{mg} / \mathrm{g})$, respectively (Fig. 7, a). When compared with the control group, TF for K, Ca and Mg have little change, whereas Na was significantly affected (PFOA: 1.42, 1.95, 3.45, 3.95, N, D), (HFPO-DA: 1.42, 1.30, 2.67, 2.67, 6.34, N) and [(PFOA + HFPO-DA): 1.42, 1.60, 2.10, 3.95, 7.13, $\mathrm{N}$, respectively (S-Table 3). At the same time, there were also differences under different levels of stress.

$\mathrm{K}$ was an essential massive nutrient element for crops, and it plays a key role in the composition and metabolism of substances in the body. Under the low concentration of the PFASs ( $5 \mathrm{mg} / \mathrm{L}$ ), the content of $\mathrm{K}$ in crops decreased sharply. It was resulted in the absorption and transport capacity of nutrients in crops to decline, resulting in metabolic disorders, and the external morphology of crops present corresponding symptoms. In addition, it was also led to the membrane lipid peroxidation of plant roots, which leads to the increase of membrane permeability and the leakage of small molecules.

$\mathrm{Ca}$ and $\mathrm{Mg}$ were playing an indispensable role in the regulation of osmotic pressure, the maintenance of metabolic balance, and the synthesis of substances in plants.(Knight et al. 2020) At the low concentration of the PFASs $(5 \mathrm{mg} / \mathrm{L})$, the content of $\mathrm{Ca}$ and $\mathrm{Mg}$ in the plant was relatively reduced. The reduction of $\mathrm{Ca}$ and $\mathrm{Mg}$ elements was not conducive to alleviating the stress and toxicity of PFASs, and might lead to increased absorption and accumulation of PFASs. Furthermore, the reduction of $\mathrm{Ca}$ and $\mathrm{Mg}$ ions was harmful to the maintenance of the normal osmotic system of root cells, and might lead to enhanced stress effects of PFASs.

Na was important to the transportation and metabolism of important substances in crops. With the increase of the PFASs stress concentration, the Na content increased. It was changing the structure and function of the cell membrane, leading to increased toxicity. Moreover, excessive sodium element had produced sodium salt stress and affect the photosynthesis of crops.

\section{Conclusion And Future Direction}

The area of PFASs to agricultural soil is more and more large, some studies have detected PFASs in cabbages, soybeans, wheat, etc.(Liu et al. 2017; Liu et al. 2019; M Zhang et al. 2019) Based on this reality, this work systematically evaluated the effects of PFASs exposure on the physiological regulations of $N$. benthamiana germination and seeding growth. The results showed that PFASs exposure will reduce the economic benefits of crops, and individuals will pose health risks by eating contaminated crops. 
Future direction 1: Since the inherent characteristic of PFASs are not degradable, we completely and totally agree that speed up the process of phasing out and replacing 'non-essential' uses of PFASs with green chemicals. (Cousins et al. 2019; Gluge et al. 2020; Zimmerman et al. 2020) Future direction 2: PFOA is manifest higher bioaccumulation capacities, but HFPO-DA have greater mobility. Which means the short-chain compounds are commonly used to replace long-chain may be more harmful that need to be building up a specifically ecotoxicity life cycle impact assessment framework (Holmquist et al. 2020) and new strategies for grouping PFASs.(Cousins et al. 2020a; Cousins et al. 2020b).

\section{Declarations}

\section{- Ethical Approval}

Not applicable.

\section{- Consent to Participate}

Not applicable.

\section{- Consent to Publish}

Approved by all authors.

\section{- Authors Contributions}

Xin Li and Wenli Hu designed research; Huinian Liu, Sihui Lu, Fangwen Hu, Zhuang Zhang, Yanni Xi and Zhu Su performed research; Huinian Liu, Yanfen Liu, Tanghuan Xie, and Chang Zhang analyzed data; and Huinian Liu, Wenli Hu, and Xin Li wrote the paper.

\section{- Funding}

National Natural Science Foundation of China (No. 51579097, 51521006 and 51879102), Science \& Technology Plan Project of Hunan Province (No. 2018SK2047).

\section{- Competing Interests}

No conflict of interest.

\section{- Availability of data and materials}

All data are fully available without restriction.

\section{References}

1. Blake BE, Cope HA, Hall SM, Keys RD, Mahler BW, McCord J, Scott B, Stapleton HM, Strynar MJ, Elmore SA, Fenton SE (2020) Evaluation of maternal, embryo, and placental effects in CD-1 mice 
following gestational exposure to perfluorooctanoic acid (PFOA) or hexafluoropropylene oxide dimer acid (HFPO-DA or GenX). Environ Health Persp 128(2):27006. https://doi.org/10.1289/EHP6233

2. Cardenas A, Gold DR, Hauser R, Kleinman KP, Hivert MF, Calafat AM, Ye X, Webster TF, Horton ES, Oken E (2017) Plasma concentrations of per- and polyfluoroalkyl substances at baseline and associations with glycemic indicators and diabetes incidence among high-risk adults in the diabetes prevention program trial. Environ Health Persp 125(10):107001. https://doi.org/10.1289/EHP1612

3. Chen $\mathrm{CH}$, Yang SH, Liu Y, Jamieson P, Shan L, Chu KH (2020) Accumulation and phytotoxicity of perfluorooctanoic acid and 2,3,3,3-tetrafluoro-2-(heptafluoropropoxy) propanoate in Arabidopsis thaliana and Nicotiana benthamiana. Environ Pollut 259:113817. https://doi.org/10.1016/j.envpol.2019.113817

4. Chen H, Munoz G, Sung Vo D, Zhang L, Yao Y, Zhao Z, Yi L, Liu M, Sun H, Liu J, Sauve S (2020) Occurrence and distribution of per- and polyfluoroalkyl substances in Tianjin, China: the contribution of emerging and unknown analogues. Environ Sci Technol 54(22):14254-14264. https://doi.org/10.1021/acs.est.0c00934

5. Chow YN, Lee LK, Zakaria NA, Foo KY (2018) Phytotoxic effects of trivalent chromium-enriched water irrigation in Vigna unguiculata seedling. J Clean Prod 202:101-108. https://doi.org/10.1016/j.jclepro.2018.07.144

6. Coperchini F, Croce L, Denegri M, Pignatti P, Agozzino M, Netti GS, Imbriani M, Rotondi M, Chiovato L (2020) Adverse effects of in vitro GenX exposure on rat thyroid cell viability, DNA integrity and thyroid-related genes expression. Environ Pollut 264:114778.

https://doi.org/10.1016/j.envpol.2020.114778

7. Cousins IT, Goldenman G, Herzke D, Lohmann R, Miller M, Ng CA, Patton S, Scheringer M, Trier X, Vierke L, Wang Z, DeWitt JC (2019) The concept of essential use for determining when uses of PFASs can be phased out. Environ Sci-Proc Imp 21(11):1803-1815. https://doi.org/10.1039/c9em00163h

8. Cousins IT, DeWitt JC, Gluge J, Goldenman G, Herzke D, Lohmann R, Miller M, Ng CA, Scheringer M, Vierke L, Wang Z (2020) Strategies for grouping per- and polyfluoroalkyl substances (PFAS) to protect human and environmental health. Environ Sci-Proc Imp 22(7):1444-1460. https://doi.org/10.1039/d0em00147c

9. Cousins IT, DeWitt JC, Gluge J, Goldenman G, Herzke D, Lohmann R, Ng CA, Scheringer M, Wang Z (2020) The high persistence of PFAS is sufficient for their management as a chemical class. Environ Sci-Proc Imp 22(12):2307-2312. https://doi.org/10.1039/d0em00355g

10. Fan L, Tang J, Zhang D, Ma M, Wang Y, Han Y (2020) Investigations on the phytotoxicity of perfluorooctanoic acid in Arabidopsis thaliana. Environ Sci Pollut R 27(1):1131-1143. https://doi.org/10.1007/s11356-019-07018-5

11. Gaballah S, Swank A, Sobus JR, Howey XM, Schmid J, Catron T, McCord J, Hines E, Strynar M, Tal T (2020) Evaluation of developmental toxicity, developmental neurotoxicity, and tissue dose in 
zebrafish exposed to GenX and Other PFAS. Environ Health Persp 128(4):47005.

https://doi.org/10.1289/EHP5843

12. Gebbink WA, Van Leeuwen SPJ (2020) Environmental contamination and human exposure to PFASs near a fluorochemical production plant: Review of historic and current PFOA and GenX contamination in the Netherlands. Environ Int 137:105583.

https://doi.org/10.1016/j.envint.2020.105583

13. Gill PK, Sharma AD, Singh P, Bhullar SS (2003) Changes in germination, growth and soluble sugar contents of Sorghum bicolor (L.) Moench seeds under various abiotic stresses. Plant Growth Regul 40:157-162. https://doi.org/10.1023/A:1024252222376

14. Gluge J, Scheringer M, Cousins IT, DeWitt JC, Goldenman G, Herzke D, Lohmann R, Ng CA, Trier X, Wang Z (2020) An overview of the uses of per- and polyfluoroalkyl substances (PFAS). Environ SciProc Imp 22(12):2345-2373. https://doi.org/10.1039/d0em00291g

15. Gredelj A, Polesel F, Trapp S (2020) Model-based analysis of the uptake of perfluoroalkyl acids (PFAAs) from soil into plants. Chemosphere 244:125534.

https://doi.org/10.1016/j.chemosphere.2019.125534

16. Gredelj A, Nicoletto C, Polesello S, Ferrario C, Valsecchi S, Lava R, Barausse A, Zanon F, Palmeri L, Guidolin L, Bonato M (2020) Uptake and translocation of perfluoroalkyl acids (PFAAs) in hydroponically grown red chicory (Cichorium intybus L.): Growth and developmental toxicity, comparison with growth in soil and bioavailability implications. Sci Total Environ 720:137333. https://doi.org/10.1016/j.scitotenv.2020.137333

17. Gomis MI, Vestergren R, Borg D, Cousins IT, Comparing the toxic potency in vivo of long-chain perfluoroalkyl acids and fluorinated alternatives. Environ Int 2018, 113, 1-9. https://doi.org/10.1016/j.envint.2018.01.011

18. Goodin MM, Zaitlin D, Naidu RA, Lommel SA (2008) Nicotiana benthamiana: its history and future as a model for plant-pathogen interactions. Mol Plant Microbe In 21(8):1015-1026. https://doi.org/10.1094/MPMI-21-8-1015

19. Hassell KL, Coggan TL, Cresswell T, Kolobaric A, Berry K, Crosbie ND, Blackbeard J, Pettigrove VJ, Clarke BO (2020) Dietary uptake and depuration kinetics of perfluorooctane sulfonate, perfluorooctanoic acid, and hexafluoropropylene oxide dimer acid (GenX) in a benthic fish. Environ Toxicol Chem 39(3):595-603. https://doi.org/10.1002/etc.4640

20. Hogue C, Governments endorse global PFOA ban, with some exemptionsï»i. C\&EN Global Enterp 2019, pp 5-5. https://doi.org/10.1021/cen-09719-leadcon

21. Holmquist $H$, Fantke P, Cousins IT, Owsianiak M, Liagkouridis I, Peters GM, An (eco)toxicity life cycle impact assessment framework for per- and polyfluoroalkyl substances. Environ Sci Technol 2020, 54, (10), 6224-6234. https://doi.org/10.1021/acs.est.9b07774

22. Houtz EF, Higgins CP, Field JA, Sedlak DL, Persistence of perfluoroalkyl acid precursors in AFFFimpacted groundwater and soil. Environ Sci Technol 2013, 47, (15), 8187-95. https://doi.org/10.1021/es4018877 
23. Knight ER, Braunig J, Janik LJ, Navarro DA, Kookana RS, Mueller JF, McLaughlin MJ, An investigation into the long-term binding and uptake of PFOS, PFOA and PFHxS in soil - plant systems. J Hazard Mater 2020, 404, (Pt B), 124065. https://doi.org/10.1016/j.jhazmat.2020.124065

24. Li J, Mutanda I, Wang K, Yang L, Wang J, Wang Y, Chloroplastic metabolic engineering coupled with isoprenoid pool enhancement for committed taxanes biosynthesis in Nicotiana benthamiana. Nat Commun 2019, 10, (1), 4850. https://doi.org/10.1038/s41467-019-12879-y

25. Li P, Oyang X, Xie X, Li Z, Yang H, Xi J, Guo Y, Tian X, Liu B, Li J, Xiao Z (2019) Phytotoxicity induced by perfluorooctanoic acid and perfluorooctane sulfonate via metabolomics. J Hazard Mater. https://doi.org/10.1016/j.jhazmat.2019.121852

26. Li P, Xiao Z, Sun J, Oyang X, Xie X, Li Z, Tian X, Li J (2020) Metabolic regulations in lettuce root under combined exposure to perfluorooctanoic acid and perfluorooctane sulfonate in hydroponic media. Sci Total Environ 726:138382. https://doi.org/10.1016/j.scitotenv.2020.138382

27. Lindstrom AB, Strynar MJ, Libelo EL (2011) Polyfluorinated compounds: past, present, and future. Environ Sci Technol 45(19):7954-7961. https://doi.org/10.1021/es2011622

28. Liu H, Hu W, Li X, Hu F, Xi Y, Su Z, Huang Y, Liu B, Zhang C (2021) Do perfluoroalkyl substances aggravate the occurrence of obesity-associated glucolipid metabolic disease? Environ Res. https://doi.org/10.1016/j.envres.2021.111724

29. Liu T, Wang M, Awasthi MK, Chen H, Awasthi SK, Duan Y, Zhang Z, Measurement of cow manure compost toxicity and maturity based on weed seed germination. J Clean Prod 2020, 245. https://doi.org/10.1016/j.jclepro.2019.118894

30. Liu Z, Lu YL, Song X, Jones K, Sweetman AJ, Johnson AC, Zhang M, Lu X, Su C (2019) Multiple crop bioaccumulation and human exposure of perfluoroalkyl substances around a mega fluorochemical industrial park, China: Implication for planting optimization and food safety. Environ Int 127:671684. https://doi.org/10.1016/j.envint.2019.04.008

31. Liu Z, Lu YL, Shi Y, Wang P, Jones K, Sweetman AJ, Johnson AC, Zhang M, Zhou Y, Lu X, Su C, Sarvajayakesavaluc S, Khan K (2017) Crop bioaccumulation and human exposure of perfluoroalkyl acids through multi-media transport from a mega fluorochemical industrial park, China. Environ Int. https://doi.org/10.1016/j.envint.2017.05.014

32. Moradi R, Pourghasemian N, Naghizadeh M (2019) Effect of beeswax waste biochar on growth, physiology and cadmium uptake in saffron. J Clean Prod 229:1251-1261. https://doi.org/10.1016/j.jclepro.2019.05.047

33. Moulick D, Santra SC, Ghosh D, Seed priming with Se alleviate As induced phytotoxicity during germination and seedling growth by restricting As translocation in rice (Oryza sativa L c.v. IET-4094). Ecotox Environ Safe 2017, 145, 449-456. https://doi.org/10.1016/j.ecoenv.2017.07.060

34. Muller CE, LeFevre GH, Timofte AE, Hussain FA, Sattely ES, Luthy RG (2016) Competing mechanisms for perfluoroalkyl acid accumulation in plants revealed using an Arabidopsis model system. Environ Toxicol Chem 35(5):1138-1147. https://doi.org/10.1002/etc.3251 
35. Olsen GW, Burris JM, Ehresman DJ, Froehlich JW, Seacat AM, Butenhoff JL, Zobel LR (2007) Half-life of serum elimination of perfluorooctanesulfonate, perfluorohexanesulfonate, and perfluorooctanoate in retired fluorochemical production workers. Environ Health Persp 115(9):1298-1305. https://doi.org/10.1289/ehp.10009

36. Pi N, Ng JZ, Kelly BC, Uptake and elimination kinetics of perfluoroalkyl substances in submerged and free-floating aquatic macrophytes: Results of mesocosm experiments with Echinodorus horemanii and Eichhornia crassipes. Water Res 2017, 117, 167-174.

https://doi.org/10.1016/j.watres.2017.04.003

37. Shan Q, Wang Y, Li J, Zhang Y, Chen K, Liang Z, Zhang K, Liu J, Xi JJ, Qiu JL, Gao C (2013) Targeted genome modification of crop plants using a CRISPR-Cas system. Nat Biotechnol 31(8):686-688. https://doi.org/10.1038/nbt.2650

38. Sznajder-Katarzynska K, Surma M, Cieslik E, Wiczkowski W (2018) The perfluoroalkyl substances (PFASs) contamination of fruits and vegetables. Food Addit Contam A 35(9):1776-1786. https://doi.org/10.1080/19440049.2018.1502477

39. Semerad J, Hatasova N, Grasserova A, Cerna T, Filipova A, Hanc A, Innemanova P, Pivokonský M, Cajthaml T (2020) Screening for 32 per- and polyfluoroalkyl substances (PFAS) including GenX in sludges from 43 WWTPs located in the Czech Republic - Evaluation of potential accumulation in vegetables after application of biosolids. Chemosphere.

https://doi.org/10.1016/j.chemosphere.2020.128018

40. Tian Y, Yao Y, Chang S, Zhao Z, Zhao Y, Yuan X, Wu F, Sun H, Occurrence and phase distribution of neutral and ionizable per- and polyfluoroalkyl substances (PFASs) in the atmosphere and plant leaves around landfills: a case study in Tianjin, China. Environ Sci Technol 2018, 52, (3), 1301-1310. https://doi.org/10.1021/acs.est.7b05385

41. Wang TT, Ying GG, He LY, Liu YS, Zhao JL (2020) Uptake mechanism, subcellular distribution, and uptake process of perfluorooctanoic acid and perfluorooctane sulfonic acid by wetland plant Alisma orientale. Sci Total Environ 733:139383. https://doi.org/10.1016/j.scitotenv.2020.139383

42. Wang TT, Ying GG, Shi WJ, Zhao JL, Liu YS, Chen J, Ma DD, Xiong Q (2020) Uptake and translocation of perfluorooctanoic Acid (PFOA) and perfluorooctanesulfonic acid (PFOS) by wetland plants: Tissue- and cell-level distribution visualization with desorption electrospray ionization mass spectrometry (DESI-MS) and transmission electron microscopy equipped with energy-dispersive spectroscopy (TEM-EDS). Environ Sci Technol 54(10):6009-6020.

https://doi.org/10.1021/acs.est.9b05160

43. Wang X, Chen M, Gong P, Wang C, Perfluorinated alkyl substances in snow as an atmospheric tracer for tracking the interactions between westerly winds and the Indian Monsoon over western China. Environ Int 2019, 124, 294-301. https://doi.org/10.1016/j.envint.2018.12.057

44. Wang X, Wang C, Zhu T, Gong P, Fu J, Cong Z (2019) Persistent organic pollutants in the polar regions and the Tibetan Plateau: A review of current knowledge and future prospects. Environ Pollut 248:191-208. https://doi.org/10.1016/j.envpol.2019.01.093 
45. Wang W, Rhodes G, Ge J, Yu X, Li H, Uptake and accumulation of per- and polyfluoroalkyl substances in plants. Chemosphere 2020, 261, 127584. https://doi.org/10.1016/j.chemosphere.2020.127584

46. Wen B, Li L, Liu Y, Zhang H, Hu X, Shan X, Zhang S (2013) Mechanistic studies of perfluorooctane sulfonate, perfluorooctanoic acid uptake by maize (Zea mays L. cv. TY2). Plant Soil 370(1-2):345354. https://doi.org/10.1007/s11104-013-1637-9

47. Wen Y, Mirji N, Irudayaraj J, Epigenetic toxicity of PFOA and GenX in HepG2 cells and their role in lipid metabolism. Toxicol In Vitro 2020, 65, 104797. https://doi.org/10.1016/j.tiv.2020.104797

48. Xiao $F$ (2017) Emerging poly-and perfluoroalkyl substances in the aquatic environment: A review of current literature. Water Res 124:482-495. https://doi.org/10.1016/j.watres.2017.07.024

49. Xiang L, Chen L, Yu LY, Yu PF, Zhao HM, Mo CH, Li YW, Li H, Cai QY, Zhou DM, Wong MH (2018) Genotypic variation and mechanism in uptake and translocation of perfluorooctanoic acid (PFOA) in lettuce (Lactuca sativa L.) cultivars grown in PFOA-polluted soils. Sci Total Environ 636:999-1008. https://doi.org/10.1016/j.scitotenv.2018.04.354

50. Xie LJ, Zhou Y, Chen QF, Xiao S, New insights into the role of lipids in plant hypoxia responses. Prog Lipid Res 2020, 101072. https://doi.org/10.1016/j.plipres.2020.101072

51. Zhang W, Zhang D, Zagorevski DV, Liang Y (2019) Exposure of Juncus effusus to seven perfluoroalkyl acids: uptake, accumulation and phytotoxicity. Chemosphere 233:300-308. https://doi.org/10.1016/j.chemosphere.2019.05.258

52. Zhang M, Wang P, Lu YL, Lu X, Zhang A, Liu ZY, Zhang Y, Khan K, Sarvajayakesavalu S (2019) Bioaccumulation and human exposure of perfluoroalkyl acids (PFAAs) in vegetables from the largest vegetable production base of China. Environ Int. https://doi.org/10.1016/j.envint.2019.105347

53. Zhang J, Kirkham MB (1993) Drought-Stress-Induced Changes in Activities of Superoxide Dismutase, Catalase, and Peroxidase in Wheat Species. Plant Cell Physiol 35:785-791. https://doi.org/10.1093/oxfordjournals.pcp.a078658

54. Zhang DQ, Wang M, He Q, Niu X, Liang Y (2020) Distribution of perfluoroalkyl substances (PFASs) in aquatic plant-based systems: From soil adsorption and plant uptake to effects on microbial community. Environ Pollut 257:113575. https://doi.org/10.1016/j.envpol.2019.113575

55. Zhao S, Fan Z, Sun L, Zhou T, Xing Y, Liu L (2017) Interaction effects on uptake and toxicity of perfluoroalkyl substances and cadmium in wheat (Triticum aestivum L.) and rapeseed (Brassica campestris L.) from co-contaminated soil. Ecotox Environ Safe 137:194-201. https://doi.org/10.1016/j.ecoenv.2016.12.007

56. Zhu H, Kannan K (2019) Distribution and partitioning of perfluoroalkyl carboxylic acids in surface soil, plants, and earthworms at a contaminated site. Sci Total Environ 647:954-961. https://doi.org/10.1016/j.scitotenv.2018.08.051

57. Zimmerman JB, Anastas PT, Erythropel HC, Leitner W, Designing for a green chemistry future. Science 2020, 367, (6476), 397-400. https:// doi.org/10.1126/science.aay3060

58. Zhou Y, Wang T, Jiang Z, Kong X, Li Q, Sun Y, Wang P, Liu Z (2017) Ecological effect and risk towards aquatic plants induced by perfluoroalkyl substances: Bridging natural to culturing flora. 


\section{Tables}

Table 1

The kit information

\begin{tabular}{|llll|}
\hline Brand & NO. & Assay Kit & Link \\
\hline Solarbio & BC0205 & CAT & http://www.solarbio.com/goods-12544.html \\
Solarbio & BC0175 & SOD & http://www.solarbio.com/goods-9124.html \\
Solarbio & BC0095 & POD & http://www.solarbio.com/goods-9116.html \\
Solarbio & BC3595 & $\mathrm{H}_{2} \mathrm{O}_{2}$ & http://www.solarbio.com/goods-9127.html \\
\hline Solarbio & BC0025 & MDA & http://www.solarbio.com/goods-9102.html \\
Solarbio & BC0035 & Soluble sugar & http://www.solarbio.com/goods-9104.html \\
\hline
\end{tabular}

Figures
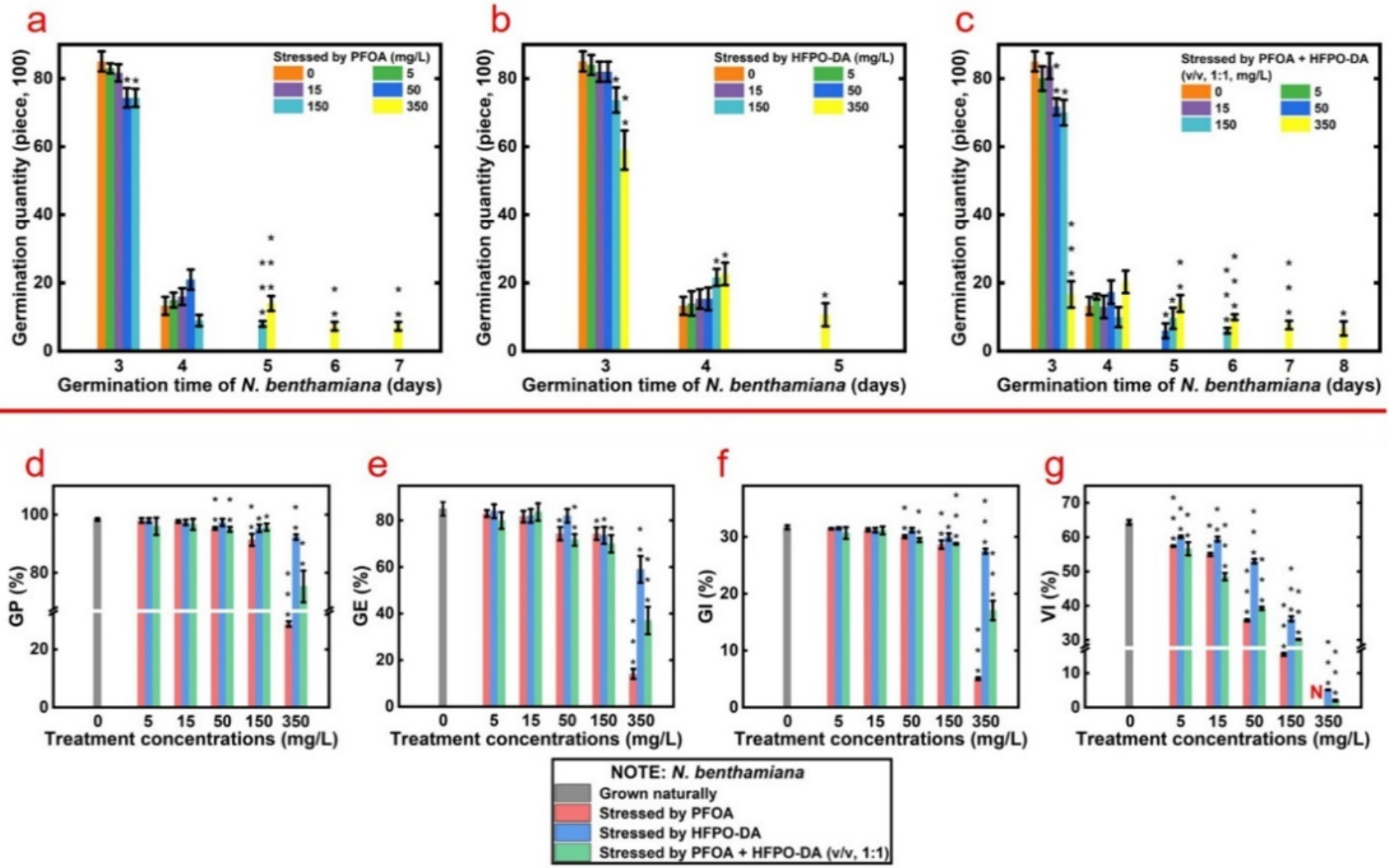
Figure 1

Effects of different concentrations of PFASs exposure on germination. a-c: germination time and quantity of seeds stressed by PFOA, HFPO-DA and (PFOA + HFPO-DA). d-f: GP, GE, GI, VI. NOTE I N: plants not obtain biomass. Each group use 100 seeds. Data were means \pm SE of three independent groups.

Asterisks indicate significant differences between the treatments and the control, where $p<0.05\left({ }^{*}\right), p<$ $0.01(* *)$ and $p<0.001(* * *)$.

a

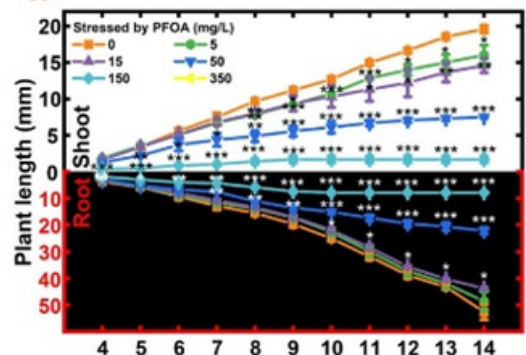

$\begin{array}{lcccccccccc}4 & 5 & 6 & 7 & 8 & 9 & 10 & 11 & 12 & 13 & 14 \\ \text { Growth time of } & N \text {. benthamiana }\end{array}$

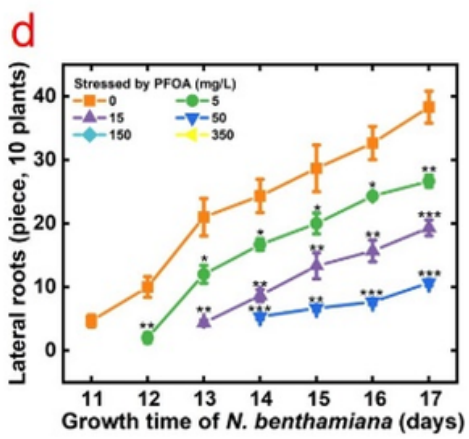

b

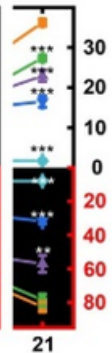

21

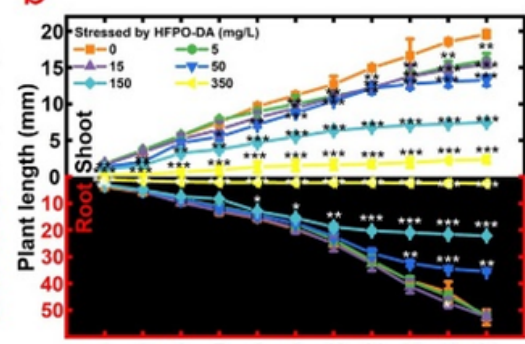

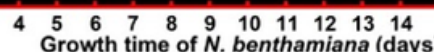

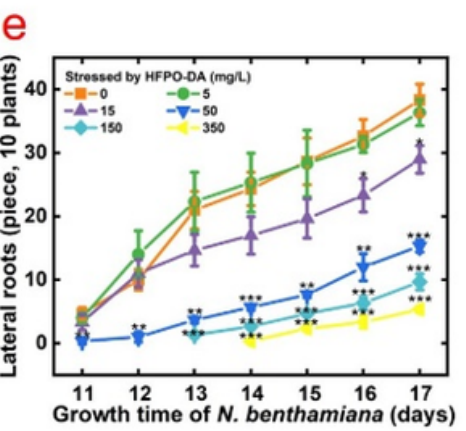

C
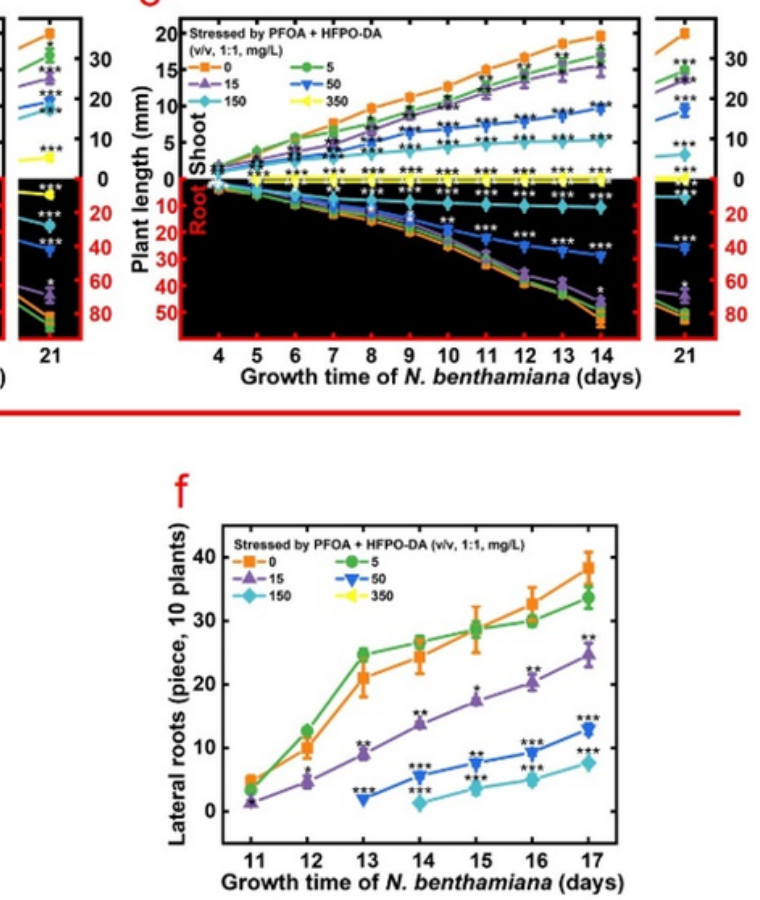

Figure 2

Effects of different levels of PFASs exposure on agronomic traits. The length of roots and shoots changes with the growth time under stressed by PFOA (a), HFPO-DA (b) and (PFOA + HFPO-DA) (c). The number of lateral roots sprouted with the stress time under stressed by PFOA (d), HFPO-DA (e) and (PFOA + HFPO-DA) (f) (The total number of 10 plants was counted). 
a

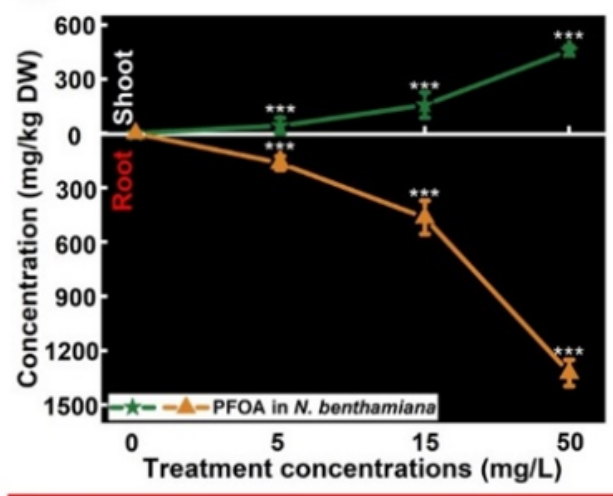

d

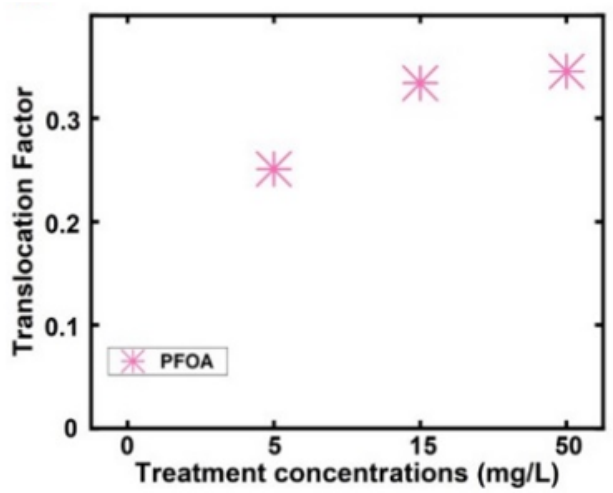

b

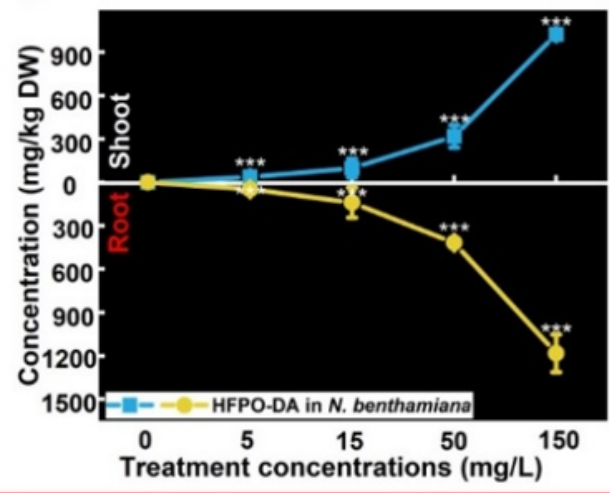

e

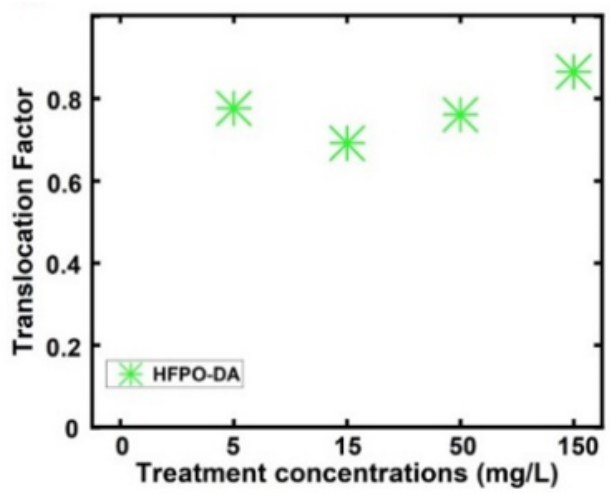

C

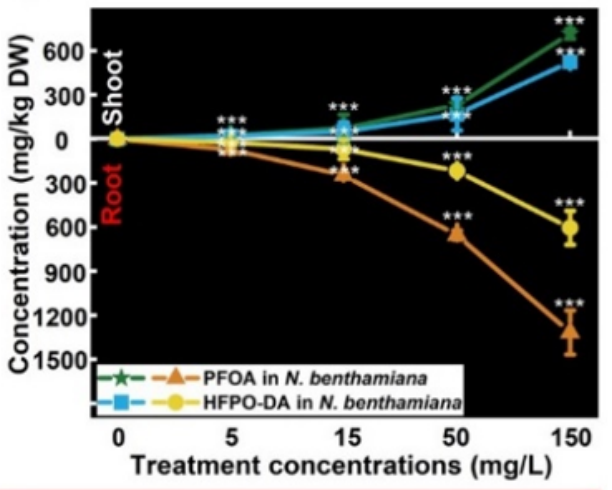

f

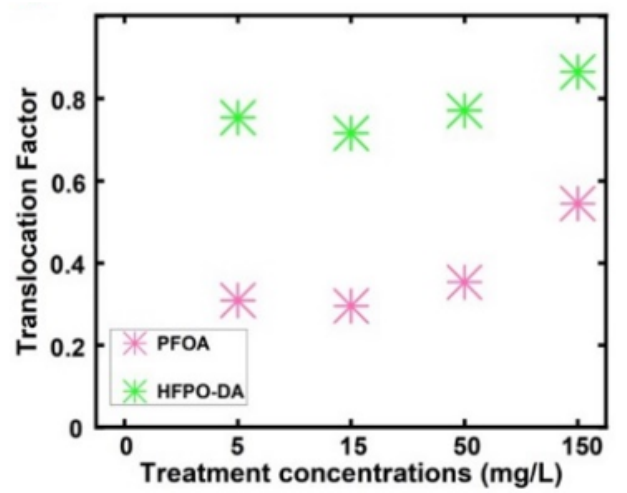

Figure 3

Emerging contaminants content after exposed 21 days. (a, d) Stressed by PFOA. (b, e) Stressed by HFPODA. (c, f) Stressed by (PFOA + HFPO-DA), v/v, 1:1. The test biomass under high concentration stressed was not obtained.
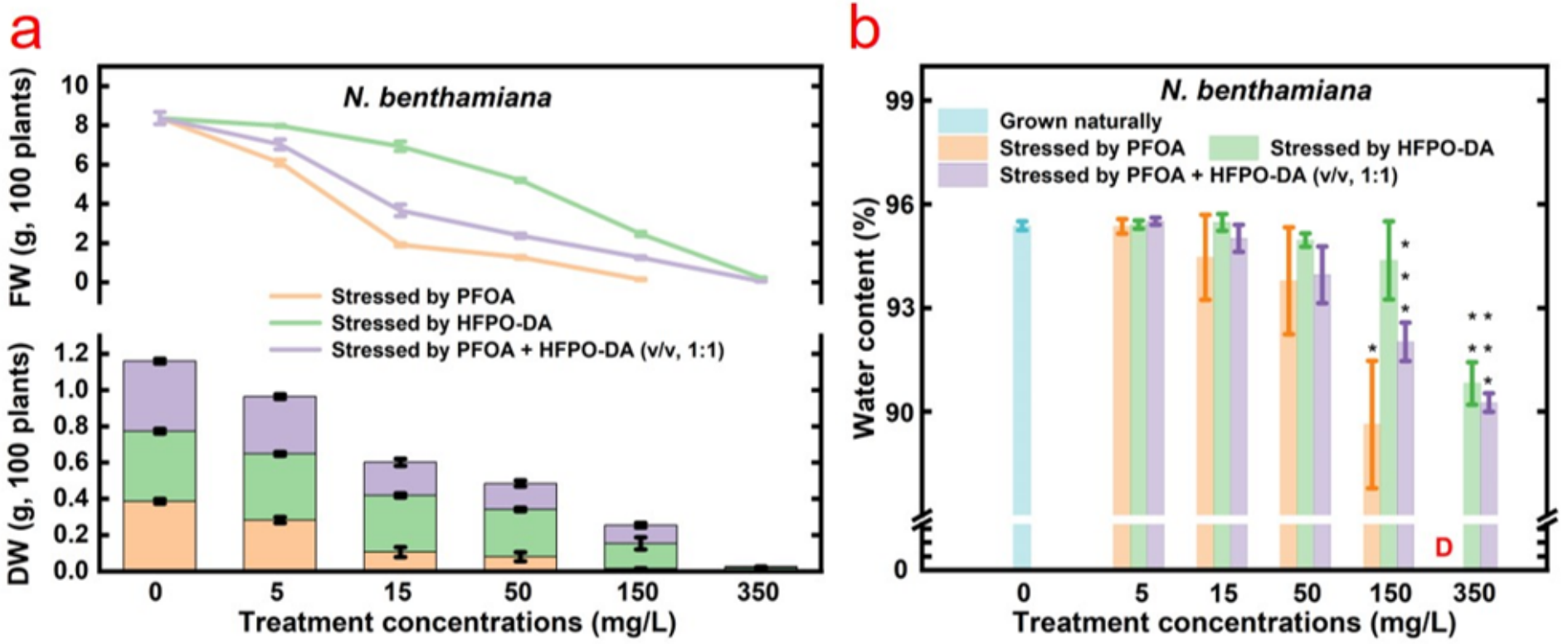

Figure 4 
Agronomic traits after stressed 21 days. (a) The fresh weight (FW) and dry weight (DW) under stressed by PFASs, the total number of 100 plants was counted. (b) The water content under stressed by PFASs. D: Plants with no signs of life. Each group use 100 plants.
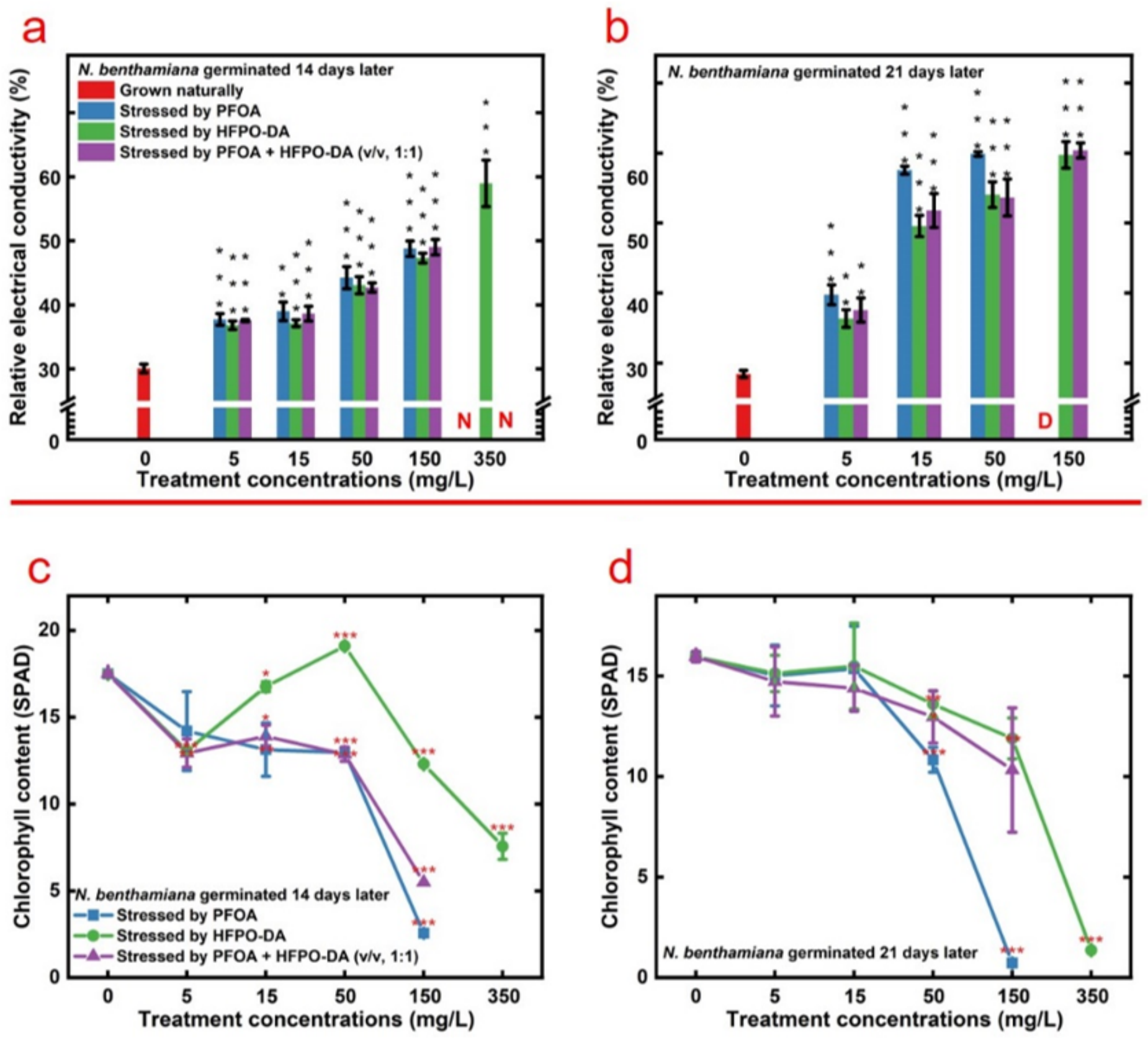

Figure 5

Physiological and biochemical indicators after stressed. The relative electrical conductivity after 14 days (a) and 21days (b) on stressed. The chlorophyll content after 14 days (c) and 21days (d) on stressed. D: Plants with no signs of life. N: Plants not obtain biomass. 
a

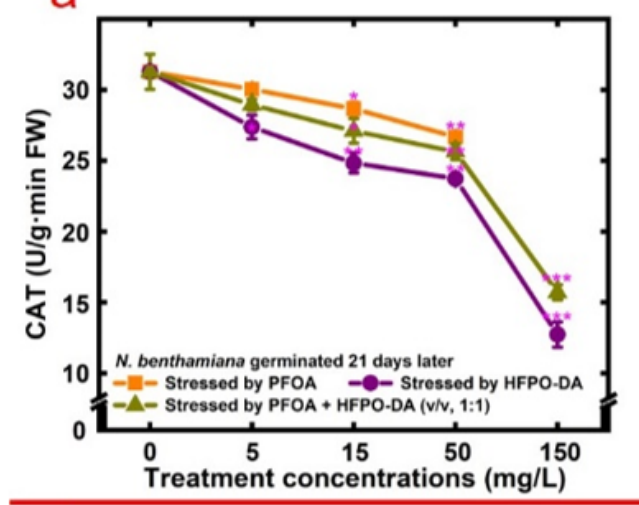

b

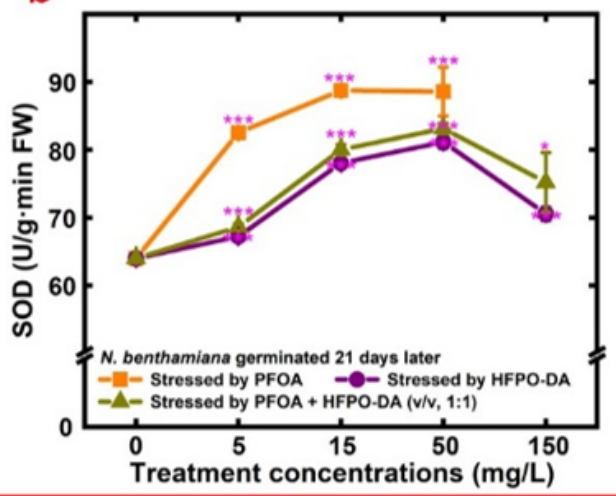

e

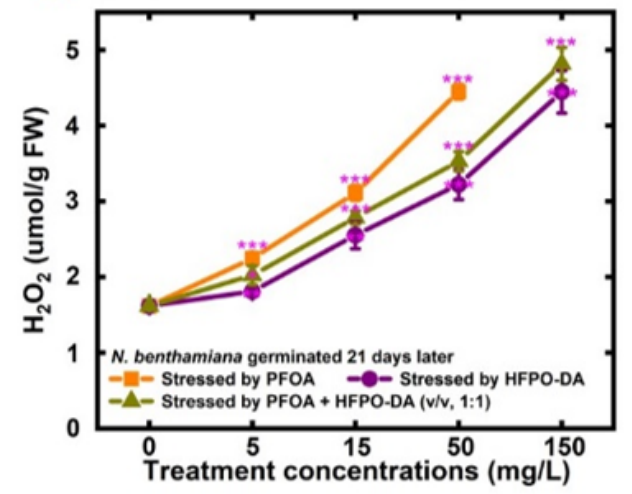

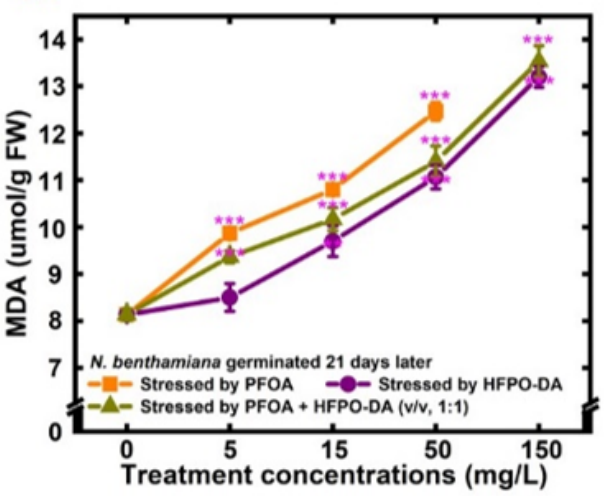

C

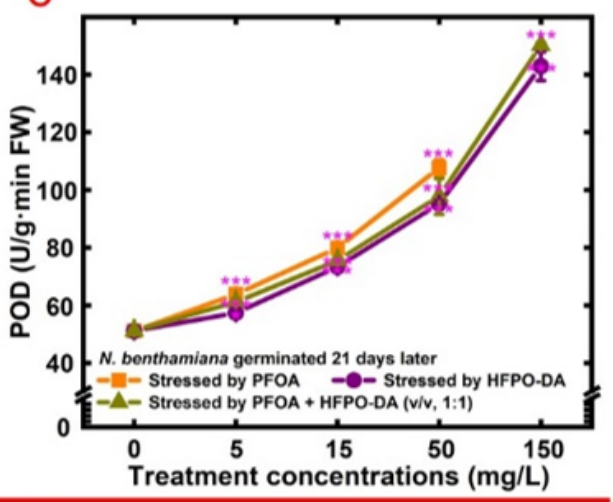

$f$

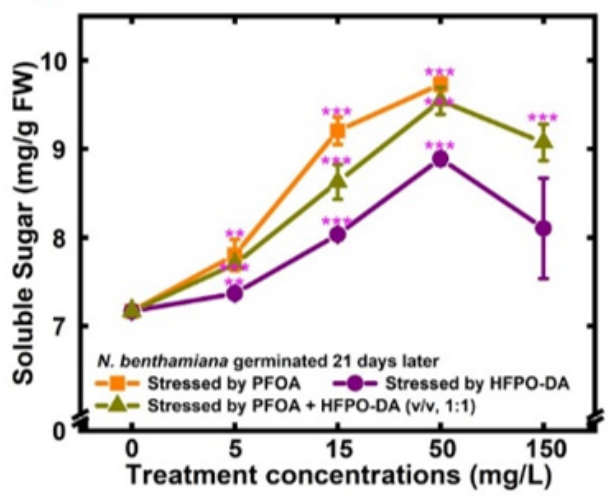

Figure 6

Physiological and biochemical indicators after stressed 21 days. (a) CAT activity. (b) SOD activity. (c) POD activity. (d) H2O2 content. (e) MDA content. (f) Soluble sugar content. The test biomass under high concentration (150 mg/L) PFOA or (PFOA + HFPO-DA) stressed was not obtained. 
a

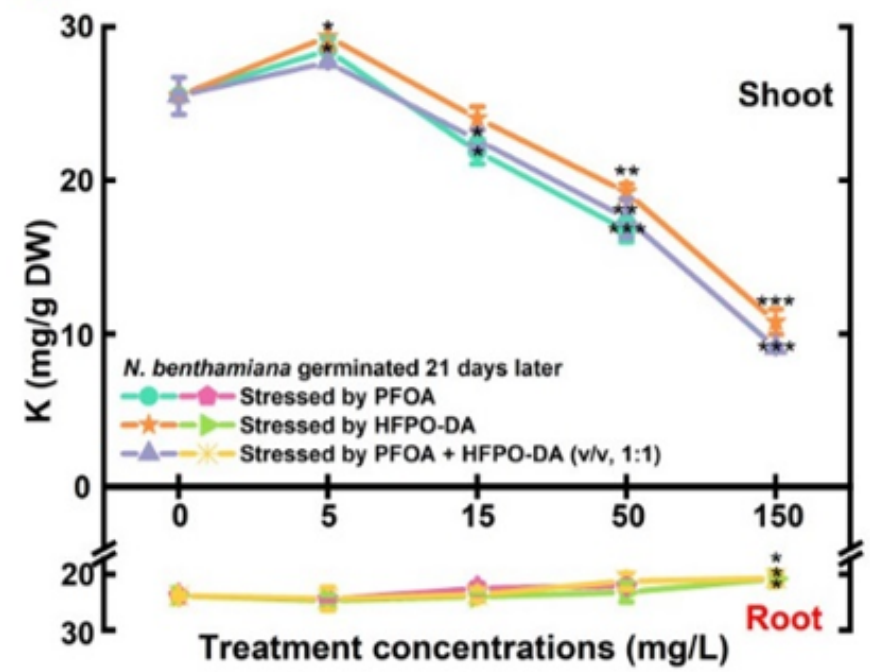

C

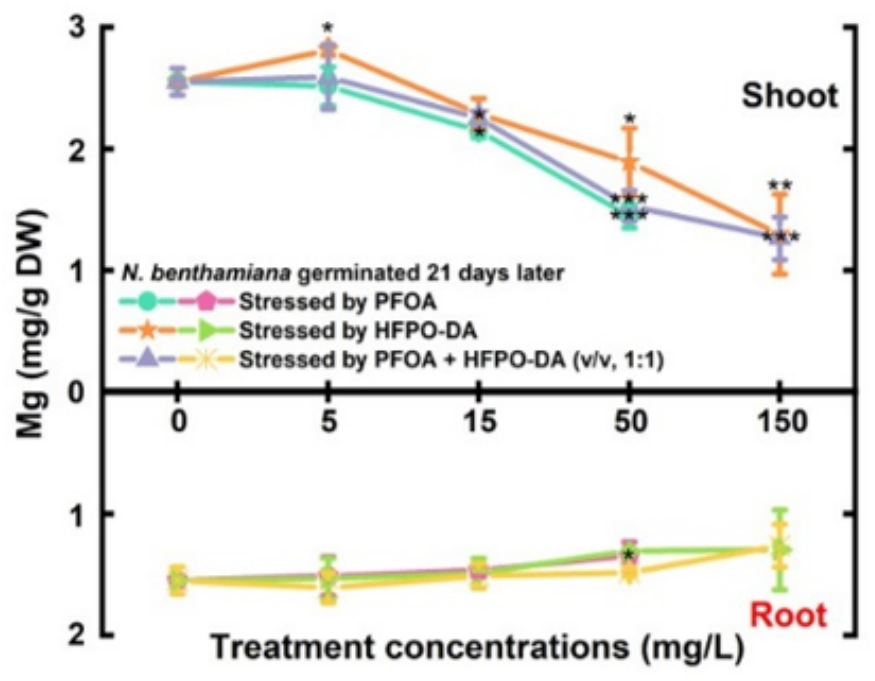

b

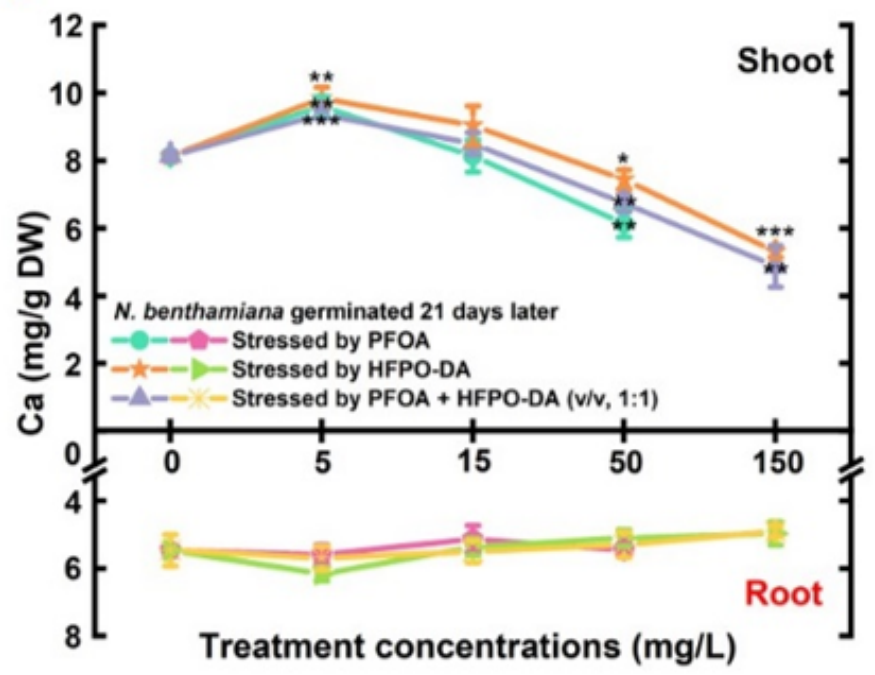

d

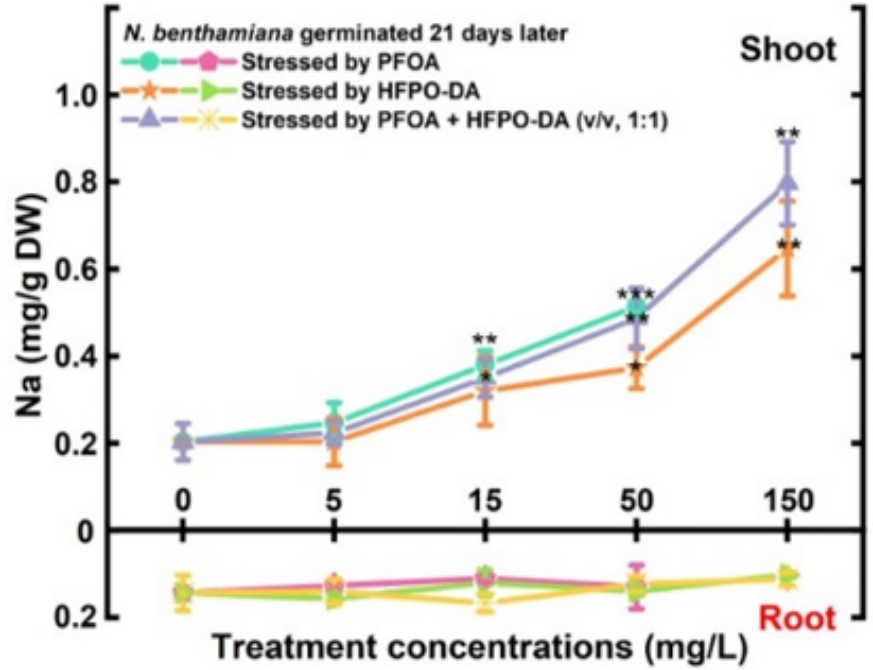

Figure 7

Mineral element content in roots and shoots after stressed 21 days. (a) K content. (b) Ca content. (c) Mg content. (d) Na content. The test biomass under high concentration (150 mg/L) PFOA or (PFOA + HFPODA) stressed was not obtained.

\section{Supplementary Files}

This is a list of supplementary files associated with this preprint. Click to download.

- SupplementalMaterial.docx 